\title{
The Preparation of Cellulose Nanocomposite Film from Isolated Cellulose of Corncobs as Food Packaging
}

\author{
M. ZULHAM EFENDI SINAGA ${ }^{1}$, SAHARMAN GEA ${ }^{* 1}$, NAMI PANINDIA ${ }^{1}$ \\ and YUAN ALFINSYAH SIHOMBING ${ }^{2}$ \\ 'Department of Chemistry, Faculty of Mathematics and Natural Sciences, University of Sumatera \\ Utara, Medan, 20155, Indonesia. \\ ${ }^{2}$ Department of Physics, Faculty of Mathematics and Natural Sciences, University of Sumatera \\ Utara, Medan, 20155, Indonesia. \\ Corresponding author E-mail: s.gea@usu.ac.id \\ http://dx.doi.org/10.13005/ojc/340166
}

(Received: August 01, 2017; Accepted: September 15, 2017)

\begin{abstract}
The cellulose nanocomposite as food packaging has been prepared from the isolated cellulose of corncobs waste. The cellulose in corncob powder was isolated through a standard isolation method with various acid and bases by the heating process. As many as $17.4 \%$ of cellulose was successfully isolated and characterized via FTIR spectroscopy, TGA and TEM. Furthermore, the isolated cellulose was partially dissolved in $\mathrm{DMAC} / \mathrm{LiCl} 8 \%$ and compressed at high temperature to produce the cellulose nanocomposite film. The isolated cellulose showed a similar functional group with the commercial cellulose, indicating the success of the isolation process. SEM analysis was conducted to several all-cellulose nanocomposites with various time of soaking. The best soaking time to perform was $60 \mathrm{~min}$. showing a good result in morphological surface analysis. Moreover, the cellulose nanocomposite film exhibited as a good food packaging material to negate the microbes growth in food.
\end{abstract}

Keywords: Cellulose, Cellulose nanocomposite film, Food packaging, Packaging bread.

\section{INTRODUCTION}

The use of plastic packaging has dominated the food industry in Indonesia, replacing the use of glass and metal packaging. The use of plastics as food packaging materials are mainly caused by its superiority in terms of a flexible form; made it easy to follow the shape of the food, easy to be labeled, not easily broken, and can be massively produced. Meanwhile, the price is affordable, and there is a wide selection of plastic materials. However, the use of plastic as packaging material has raised various environmental problems, such as; unrecyclable, cannot be naturally decompossed by microbes in the soil, the accumulation of plastic waste that causes pollution and damage to the 
environment. Another weakness is the main ingredient of plastic that derived from petroleum, its resources are dwindling and can not be renewed. Studies have shown that the use of biopolymerbased materials may minimize the packaging waste production. Moreover, it consecutively solves the waste disposal problem and to some extent owing to its biodegradability. It is based on research that have been conducted by using materials from nature to produce an environmentallyfriendly packaging material. Comprehensive research has been done to develop the alternative of packaging materials by decreasing the environmental impact of the petroleum based on packaging materials.

Corn is one of the agricultural products that are widely produced in Indonesia, particularly in North Sumatra. Data showed that the development of corn agriculture in North Sumatra, according to the Central Bureau of statistics in 2015 was $1,519,407$ tons. Moreover, based on the data generated, the corncob waste was as much as 455 , 822 tons in 2015. Several studies have been reported to utilize the corncobs waste as bioethanol feed livestock. Cellulose is the most abundant natural biopolymer and is a linear homopolysaccharide composed of $\beta$-D-glucopyranose units connected by $\beta-1-4-$ linkages with a repeating unit of cellobiose 2. Cellulose consists of both crystalline and amorphous domains. There are three hydroxyl groups in a monomer of the cellulose structure that form hydrogen bonds, which possesses a vital role in the physical properties and crystalline packing of cellulose 3 . The high content of cellulose in corncobs can be used as a source of cellulose which can then be used for making the cellulose nanocomposite film that serves as a food packaging material and is environmental friendly as it can be degradable in nature.

Composite is a mixture of two or more substances which generally has different properties, so that the final results will produce a material which has new or unique properties result of the combination of material properties which are mixed. Currently, there is a development of a single composite such as the composite cellulose (all-cellulose composite), where the matrix is only cellulose. ${ }^{4-5}$ However, as the development of technology nowadays has increased significantly, a single composite that has been chopped as nanoparticles has been produced.

\section{MATERIAL AND METHODS}

\section{Materials}

The materials used in the research were corncobs, $\mathrm{NaOH}$ pellets, $\mathrm{NaOCl}_{(\mathrm{c})} 12 \%, \mathrm{H}_{2} \mathrm{O}_{2(\mathrm{c})} 30 \%$, $\mathrm{NaNO}_{2}, \mathrm{Na}_{2} \mathrm{SO}_{3}, \mathrm{HNO}_{3(\mathrm{c})} 65 \%$, Dimethyl acetamide (DMAC), and $\mathrm{LiCl}$. These materials were purchased from Merck \& Co.

\section{METHODS}

\section{Isolation of cellulose from corncob}

A total of $75 \mathrm{~g}$ of powdered corncobs was added in a beaker glass, then 1 litre of $\mathrm{HNO}_{3}(3.5 \%)$ and $1 \mathrm{mg}$ of $\mathrm{NaNO}_{2}$ were added and heated at $90{ }^{\circ} \mathrm{C}$ for $2 \mathrm{~h}$ with constant stirring on a hot plate. Then, the mixture was filtered, and washed until the filtrate residue reached the neutral $\mathrm{pH}$. The filtrate was then added with $375 \mathrm{~mL}$ of $\mathrm{NaOH}(2 \%)$ and heated for $1 \mathrm{~h}$ at $50^{\circ} \mathrm{C}$ with constant stirring on a hot plate, then, it was filtered and washed until the filtrate residue reached the neutral $\mathrm{pH}$. The filtrate was then added with $500 \mathrm{~mL}$ of $\mathrm{NaOCl}(1.75 \%)$ and heated at $70{ }^{\circ} \mathrm{C}$ for $30 \mathrm{~min}$. with constant stirring on a hot plate, filtered and washed until the filtrate residue reached the neutral $\mathrm{pH}$. The filtrate was then added with $500 \mathrm{~mL} \mathrm{NaOH}(17.5 \%)$ and heated at $80^{\circ} \mathrm{C}$ for $30 \mathrm{~min}$. with constant stirring on a hot plate, then it was filtered and washed until the filtrate residue reached the neutral $\mathrm{pH}$. The filtrate was then added with $250 \mathrm{~mL}$ of $\mathrm{H}_{2} \mathrm{O}_{2}(10 \%)$ and heated at $60{ }^{\circ} \mathrm{C}$ for $15 \mathrm{~min}$. with constant stirring on a hot plate, then, it was filtered and washed until the filtrate residue reached the neutral $\mathrm{pH}$. Furthermore, the filtrate was dried at $60^{\circ} \mathrm{C}$ (cellulose) in the oven, and stored in a desiccator 6 . The cellulose obtained were characterized by using FTIR, TGA, and TEM

\section{Preparation of cellulose nanocomposite film}

The cellulose was activated by immersion process in distilled water, acetone, and $N, N$ dimethylacetamide (DMAc) respectively, for $1 \mathrm{~h}$ at room temperature for each solvent. After that, the activated cellulose was dissolved in DMAc/LiCl $(8 \%)$ (ratio $1: 10)$ solvent with the variations of dissolution time in $0,30,60,90,120$, and 150 minutes at room temperature. Moreover, the cellulose was dried in the oven at $80{ }^{\circ} \mathrm{C}$ and then pressed at a high temperature of $150{ }^{\circ} \mathrm{C}$ for $1 \mathrm{~h}$ to prepare all-cellulose nanocomposite film. Then, all-cellulose nanocomposite film was tested 
for their thermal properties by TGA, surface analysis using SEM, crystallinity test by $\mathrm{XRD}$, tensile strength and total number plates test for the application of the film.

\section{RESULTS AND DISCUSSION}

Isolated cellulose from corncob and preparation of all-cellulose nanocomposite film

After a delignification, bleaching, and purification of corn cobs have been conducted, the white cellulose powder was produced. For $75 \mathrm{~g}$ of corncobs powder used, it would produce 13.03 grams of cellulose $(17.4 \%$ of the initial mass of corncobs powder). The cellulose produced was subsequently and partially dissolved in DMAc/LiCl $8 \%(1: 10)$, which wiould give a gel and then compressed at hot temperature to produce cellulose nanocomposite film.

\section{The functional groups analysis using FT-IR spectroscopy}

The functional groups of cellulose which was isolated from corncobs with commercial cellulose shown the same pattern. It indicated that the isolation of cellulose from corncobs was successful. The results of FTIR analysis of each sample can be seen in Fig. 1 and Table. 1.

The presence of acetyl ester groups on hemicellulose or carboxyl groups on ferulic acid

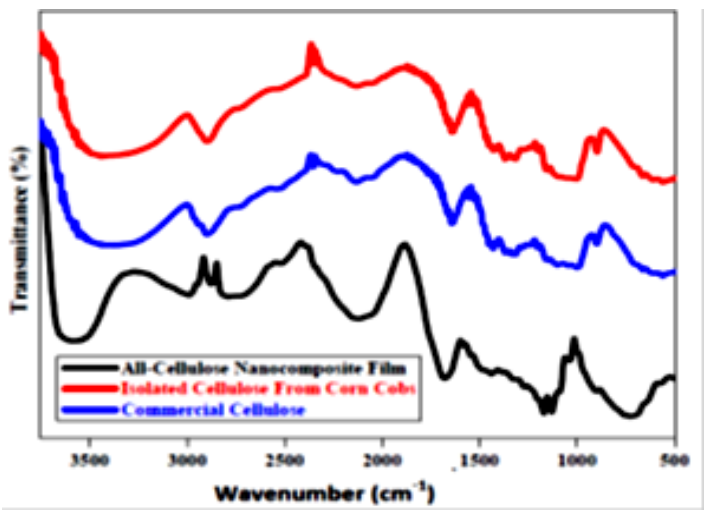

Fig. 1. The FTIR spectra of the samples and p-coumaric on lignin, are represented in the absorption wavelength around $1700 \mathrm{~cm}^{-1}$ which confirms the $\mathrm{C}=\mathrm{O}$ group ${ }^{7}$. According to the Fig. 1, the absorption wavelength around $1700 \mathrm{~cm}^{-1}$ was not visible, so it can be concluded that the content of nanocellulose had been lost during the treatment process. Moreover, the corn cob cellulose insulation has been successfully carried out. For the all-cellulose nanocomposite films, it produced the same functional groups band recorded with cellulose, but there was a movement of wavenumber at this area due to the dilution effect of DMAc/ $\mathrm{LiCl}$ as a solvent.

\section{TEM}

The size of cellulose which was isolated from corncob was determined by TEM using the ImageJ program (Fig. 2). Based on the test results, the size distribution of cellulose isolated from corncobs was between 2.5 to $4 \mathrm{~nm}$, while the average size was $2.8 \mathrm{~nm}$.

\section{XRD}

Based on the results of XRD analysis (Fig. 3), the isolated cellulose and all-cellulose nanocomposite films at 0 minute were still having crystal in their compositions.

However, the longer the dissolution time, the crystallinity properties tend to decrease. The dissolution process will result in a decrease in the size of the crystals and this happened because of the solvent can penetrate the space between the amorphous and crystalline so that the chain will be dissolved 5,8,9.

\section{The TGA test results}

Based on the results of TGA (Fig. 4), it is noticed that the starting point of the isolated cellulose decomposition was $331^{\circ} \mathrm{C}$ while all-Cellulose nanocomposite was $238{ }^{\circ} \mathrm{C}$. The highlight of the isolated cellulose degradation was at $368{ }^{\circ} \mathrm{C}$ while all-Cellulose nanocomposite was

Table. 1: The functional groups recorded from the samples

\begin{tabular}{lccc}
\hline Functional groups & $\begin{array}{c}\text { Isolated cellulose } \\
\text { from corncobs }\left(\mathrm{cm}^{-1}\right)\end{array}$ & $\begin{array}{c}\text { Commercial cellulose } \\
\left(\mathrm{cm}^{-1}\right)\end{array}$ & $\begin{array}{c}\text { All-cellulose nanocomposite } \\
\text { film }\left(\mathrm{cm}^{-1}\right)\end{array}$ \\
\hline Stretching vibration O-H & 3406.29 & 3367.71 & 3560.59 \\
Stretching vibration C-H & 2897.08 & 2897.08 & 2877.79 \\
Stretching vibration C-O-C & 1149.57 & 1099.43 & 1130.29 \\
\hline
\end{tabular}


at $255^{\circ} \mathrm{C}$. Residues of the isolated cellulose were $9.75 \%$ while the all-cellulose nanocomposite was $25.38 \%$. In average, it showed that the thermal stability of the all-cellulose nanocomposite was

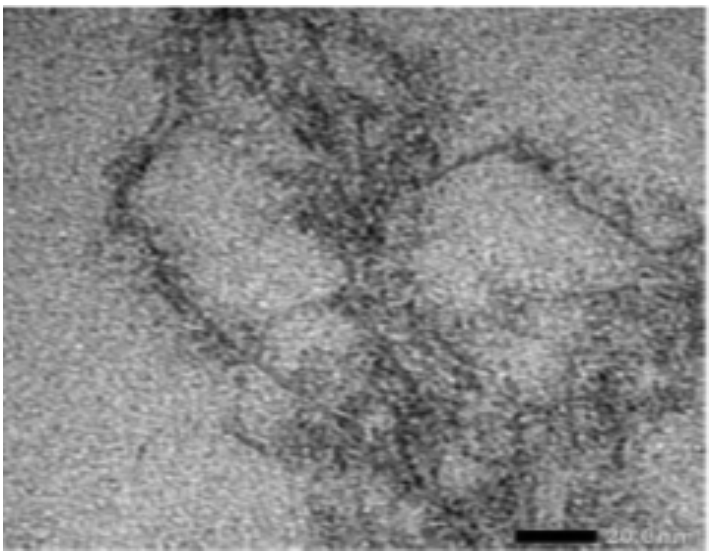

lower than the cellulose. This was due to the effect of dissolving the cellulose in $\mathrm{LiCl} / \mathrm{DMAc}$ and the degree of crystallinity of all-cellulose nanocomposite that was lower than the cellulose.

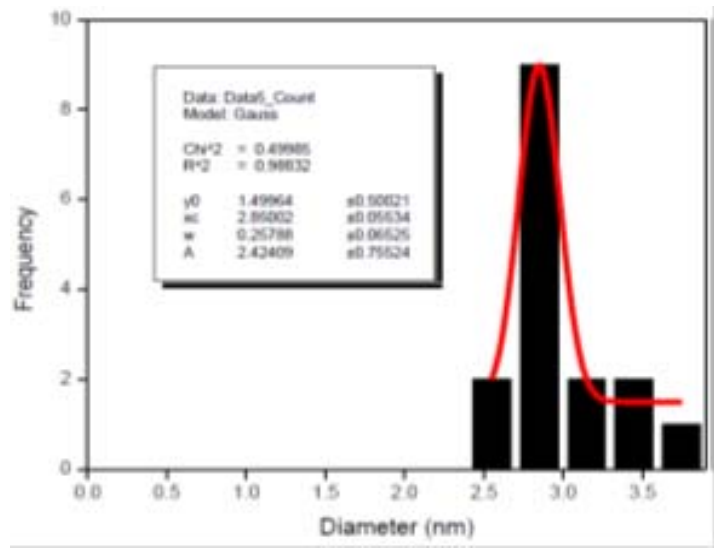

Fig. 2. TEM of isolated cellulose from corncobs
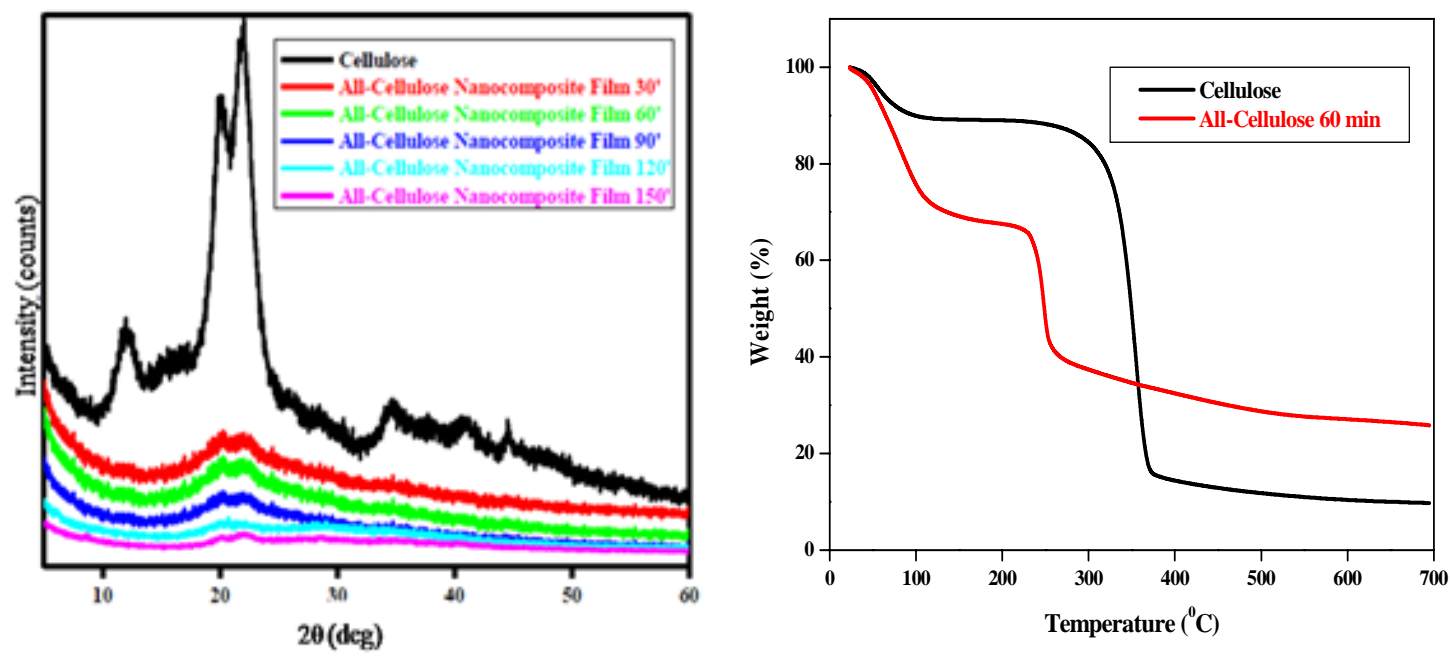

Fig. 3. XRD of isolated cellulose and cellulose nanocomposite films

\section{Tensile Strength}

Mechanical properties are one of the important properties of a composite and also in the manufacture of a food packaging. Based on the tensile strength results (Fig. 5), it can be concluded that the best mechanical properties were owned by a sheet of all-cellulose nanocomposite which were soaked for $60 \mathrm{~min}$. in $\mathrm{LiCl} / \mathrm{DMAc}(8 \%)$ with the values of tensile strength of $2.254 \mathrm{MPa}$, elongation at break
$21.55 \%$ and modulus of elasticity of 0.1045 respectively.

\section{SEM Analysis}

To determine the surface of all-cellulose composite produced, SEM analysis has been conducted. Based on Fig. 6, it can be seen that the surface of all cellulose nanocomposite which was dissolved partially in $\mathrm{LiCl} / \mathrm{DMAc}(8 \%)$ for 
$60 \mathrm{~min}$. has a more tidy surface compared to the surface of all cellulose nanocomposite with different time of dissolution. It might be due to the longer the dissolution process, which made the surface of all-cellulose more soluble. The tidier surface of the all-cellulose nanocomposite also affects the value of the tensile strength of all-cellulose nanocomposite.

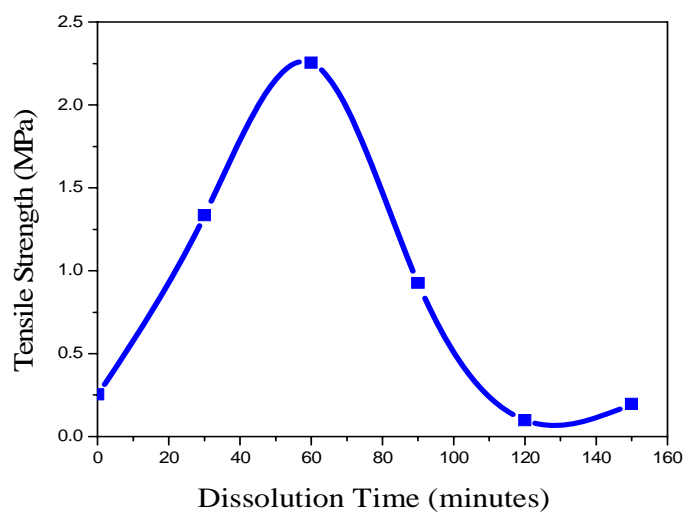

\section{Total plate count test}

The all-cellulose nanocomposite application to the food was needed to know if the resultant composite may block or reduce the damage to the food from external factor such as microbes that are not profitable. In this study, the all-cellulose nanocomposite was applied to wrap the bread for several days and the results have been shown in Fig. 7 .

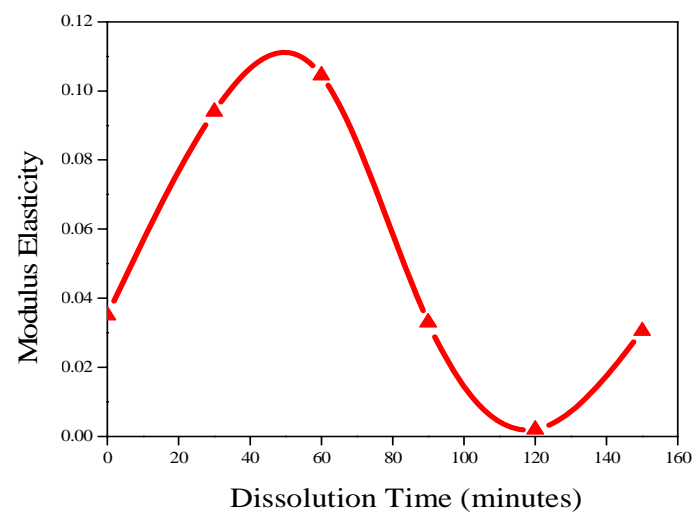

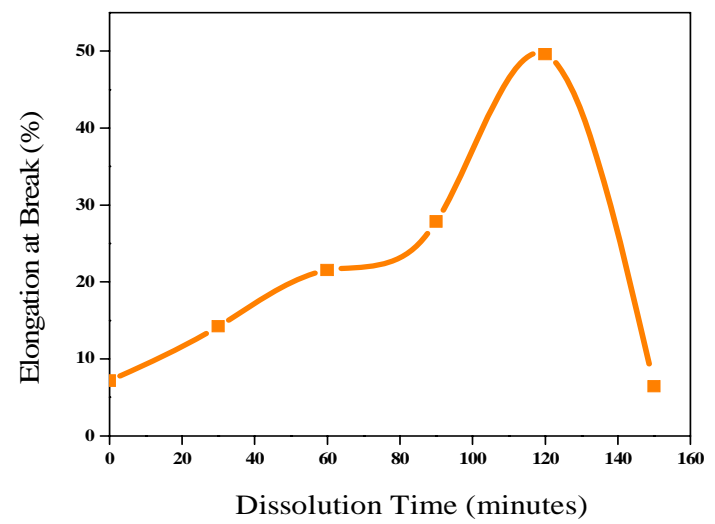

Fig. 5. The tensile strength test results
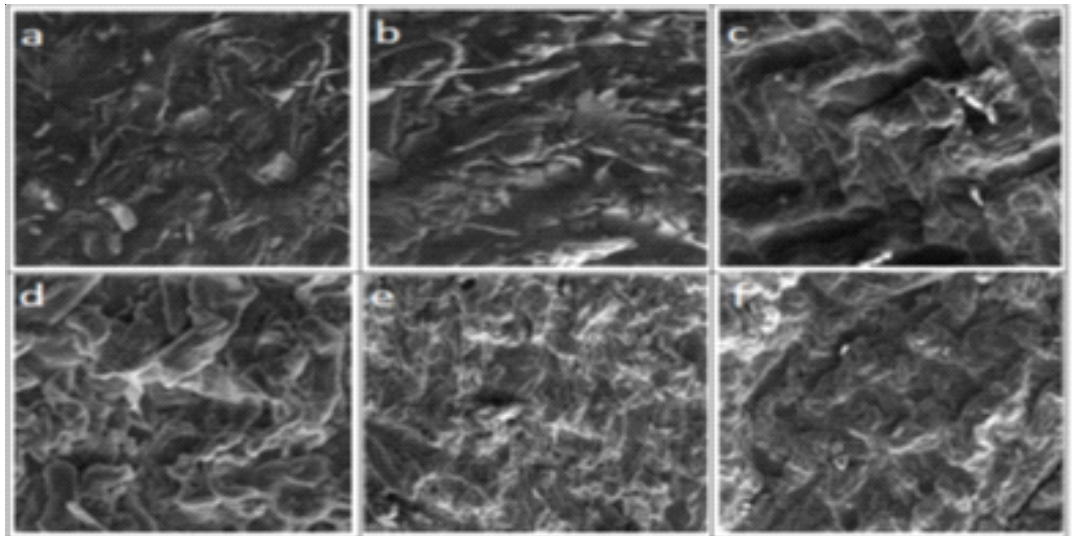

Fig. 6. SEM of all-cellulose nanocomposite: (a) $0 \mathrm{~min}$, (b) $30 \mathrm{~min}$, (c) $60 \mathrm{~min}$, (d) $90 \mathrm{~min}$, (e) $120 \mathrm{~min}$, (f) $150 \mathrm{~min}$ 


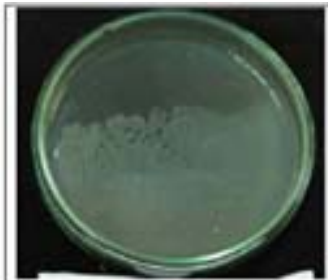

a

(ControlDay-2)

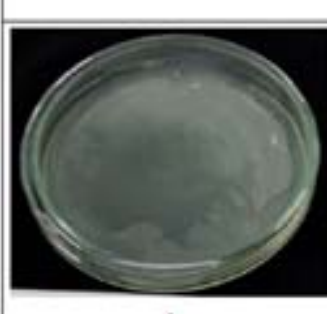

a

(Control Day-4)

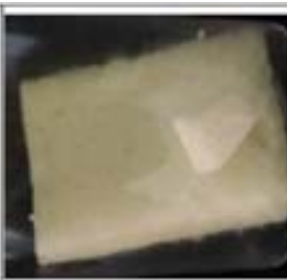

b

(Controlled Bread

Day-2)

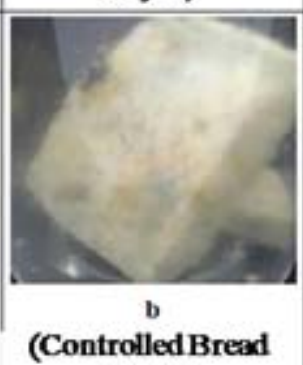

Day-4)

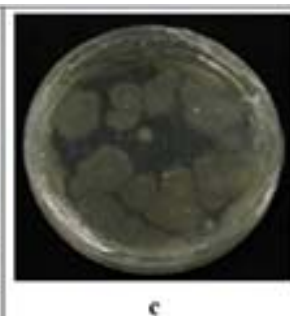

TreamentDay-2

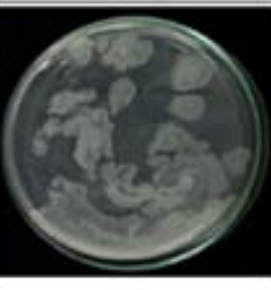

Treament Day-4

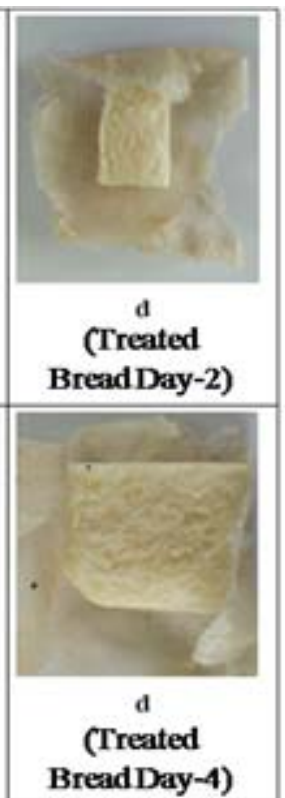

BreadDay-4)

Fig. 7. The total plate count test result of all-cellulose nanocomposite as bread wrapping

\section{CONCLUSION}

From the research that has been done, it can be concluded that the cellulose from corncobs have been isolated as evidence by FTIR, wherein the functional group of cellulose isolated from corncobs in accordance with commercial cellulose. All-cellulose produced nanocomposite which has the potential as food packaging materials.

\section{ACKNOWLEDGEMENT}

The authors would like to send gratitude to the Rector of University of Sumatera Utara for the financial support towards this research in the TALENTA Project 2016.

\section{REFERENCES}

1. Rhim, J. W.; Ng, P. K. W. Crit. Rev. Food Sci. Nutr. 2007, 47, 411-433.

2. Abdul Khalil, H. P.; Davoudpour, Y.; Islam, M. N.; Mustapha, A.; Sudesh, K.; Dungani, R.; Jawaid, M. Carbohydrate Polymers, 2014, 99, 649-665.

3. Gea, S.; Bilotti, E.; Reynolds, C. T.; Soykeabkeaw, N.; Peijs, T. Mater. Lett. 2010, 64(8), 901-904.

4. Huber, T.; Pang, S.; Staiger, M. Composites Part A: Applied Science and Manufacturing, 2012, 43(10), 1738-1745.

5. Nishino, T.; Matsuda, I.; Hirao, K.
Macromolecules, 2004, 37(20), 7683-7687.

6. Ohwoavworhua, F. O.; Adelakun, T. A. Tropical Journal of Pharmaceutical Research. 2005, 4(2), 509-516.

7. Alemdar, A.; Sain, M. Bioresour. Technol. 2008, 99(6), 1664-1671.

8. Duchemin, B. J. C.; Mathew, A. P.; Oksman, K. Compos. Part A Appl. Sci. Manuf. 2009, 40(12), 2031-2037.

9. Yousefi, H.; Nishino, T.; Faezipour, M.; Ebrahimi, G.; Shakeri, A.; Morimune, S. Adv. Compos. Lett. 2010, 19(6), 190-195. 